\title{
Research on the Use of the Artificial Intelligence by Management of the Economic System of the State
}

\author{
Olena Parubets \\ Department of Finance, Banking and \\ Insurance \\ Chernihiv National University of \\ Technology \\ Chernihiv, Ukraine \\ olena.parubets@gmail.com \\ Dmytro Sugonyako \\ Department of Public Administration \\ and Organizations Management \\ Chernihiv National University of \\ Technology \\ Chernihiv, Ukraine \\ dmytro.sugonyako@gmail.com
}

\author{
Olena Panchenko \\ Department of Finance, Banking and \\ Insurance \\ Chernihiv National University of \\ Technology \\ Chernihiv, Ukraine \\ pan68@ukr.net
}

\author{
Olena Bazilinska \\ Department of Finance \\ National University of Kyiv-Mohyla \\ Academy \\ Kyiv, Ukraine \\ olena.bazilinska@gmail.com
}

\begin{abstract}
In conditions of the rapid development of the digital economy and information knowledge of the society, the need in the research of problems and perspectives of the artificial intelligence study and its influence on the process of the economic system management of the state is growing. Within the article, the structure of the artificial intelligence is investigated, the analysis of directions and indicators of its use in various spheres of the economic activity is conducted. Main threats of the macro- and micro-character and problems of the artificial intelligence development are revealed. Measures to enhance the use of the artificial intelligence in managing the economic system of Ukraine are proposed. The main ones are the improvement of the state regulation system in the field of the artificial intelligence implementation and development, in particular through the state support of start-up projects, creation of appropriate digital infrastructure, development of the publicprivate partnership in the field of innovation.
\end{abstract}

Keywords - digital economy, artificial intelligence, technologies, management, economic system

\section{INTRODUCTION}

In today's conditions of the digital economy development, it is difficult to find a sphere of the economic activity in which there would be no examples of the artificial intelligence implementation. As a kind of the digital technology, the artificial intelligence is at the initial stage of its introduction into the economic and financial system of Ukraine. Increasing the level of the competitiveness of our state at the world level requires the widespread introduction of cognitive technologies based on the use of the artificial intelligence in the activities of subjects of various types of economic activity. Adaptation of the latter to the change of conditions of business under the influence of the introduction of the artificial intelligence systems necessitates the study of the problems and prospects of the development of this intelligence for the transformation of existing state-of-the-art business models and the provision of a digital security system. The decisionmaking process at all levels of economic processes management takes place under conditions of uncertainty of the result, so it is very important to conduct a study on identifying problems and developing perspective directions of the development of the artificial intelligence in the national practice.

Theoretical, methodological and scientific-practical aspects of the research of the artificial intelligence introduction in various spheres of the economic activity are reflected in the works of many domestic and foreign scientists and researchers.

The authors of the work [1] under the artificial intelligence understand one of the sections of the computer science, which is being mostly under the development today. It is emphasized that there are more than 150 definitions of the concept of the "artificial intelligence". Given this at the present stage of the development of science and technology, the development of a trans-disciplinary paradigm, which involves the inclusion of scientific results in the processes of the social making of economic and political decisions, is required.

As it is noted by the American researcher J. Barrat [2], gradual transition to the hegemony of computers would pass quietly and safely if not for the intelligence. Due to the latter, computer systems will behave unpredictably throughout their usable time.

The Italian philosopher Donata Francescato [3] states that in the context of the artificial intelligence spread, there is an intellectual revolution that is not like the industrial and computer revolution. Artificial intelligence can bring widespread job cuts in many areas of the economy, mostly low-paid. At the same time, the use of the artificial intelligence will lead to huge profits for the companies that do not use a lot of human labor in their activities.

According to the Swedish philosopher N. Bostrom, the rapid development of the computer technology makes it 
possible to create the artificial intelligence that can match or exceed the human mind. The author believes that the death of humankind can be caused by the rapid development of the artificial intelligence as a super-mind. In the context of the likelihood of the existential threat to humanity from the party of the artificial intelligence, it is necessary to make a concerted effort on a global scale [4].

The English physicist S. Hawking [5] states that the role of the artificial intelligence in the history of the humankind is ambiguous and the latter can be both a positive and a negative factor in the social development of the society. At the same time, the artificial intelligence is considered from two positions. With regard to the former, it is emphasized that the latest achievements of civilization can lead to the degradation of the individual consciousness. The second assumes that a well-implemented artificial intelligence is capable of solving most of the problems of the modern world.

In the course of investigation of the artificial intelligence on the labor market, the professor from Italy P.Tullinni [6] points to its innovative nature and powerful influence on individual and collective labor relations. The paper focuses on the increasing use of the artificial intelligence in the industrial environment, which creates new legal and social problems that relate to the replacement of standard work by robotics. It is noted, that it is necessary to improve the system of the employment and labor law by means of rethinking the methods of protecting human labor and maintaining employment guarantees for the able-bodied population.

In the work of [7] is noted, that in current conditions, the digitization not only of individual sectors of the economy but of the whole economic system is taking place. Domestic digital capital is in the process of being formed, and further development of the digital economy in Ukraine is linked to the expansion of the use of digital platforms, based on the block-chain technology.

Creation of the artificial intelligence systems requires the use of mathematical tools, based on the use of neural network theory techniques and fuzzy logic to solve a range of intellectual problems in economics [8]. Personal digital technologies become increasingly complex and increasingly dependent on peripherals and act as a living ecosystem. In the future, the production of similar products will receive a digital component in the form of embedded microchips [9].

By investigating the impact of the artificial intelligence on finances, the Polish scientists J. Balicki [10] points to the availability of the artificial intelligence systems which are significant for the computer power. The artificial intelligence implemented on the supercomputer will increase the level of security of the financial market and create preconditions for deciding on the mitigation of future banking crises. In addition, artificial intelligence is useful not only for optimizing investment in the stock market, but also for researching the reliability of potential borrowers.

D. Markoff [11] notes that works are becoming more and more active in our lives. Based on the study of many scientists' views on the problem of the artificial intelligence development, the author concludes that the way we design autonomous machines and how we interact with them determines the nature of the society and the economy.

The artificial intelligence spectrum in today's economic and financial systems is quite diverse and in many cases is accompanied by the use of robots. In this aspect, it is quite interesting to study the research of V.P. Karchevsky [12] aimed at teaching robots based on scientific developments and methods of the teaching of the traditional pedagogy. According to the author for the further successful development of robotics, it is necessary to conduct a deeper study of psychological and pedagogical problems in the process of human learning.

Despite significant achievements of scientists, the issues regarding the introduction of artificial intelligence into the system of the economic system management of the state to ensure its stability and sustainable development have not been addressed thoroughly and need further research. On this basis, a comprehensive study of the directions of the artificial intelligence use in the conditions of the development of the digital economy and the Internet in the management of economic and financial systems of the state is a timely and a relevant scientific task.

The purpose of the article is to analyze the influence of the artificial intelligence on modern economic processes and study problems and perspective directions of its development in the management of the economic and financial systems of Ukraine. Scientific novelty of the obtained results and the above-mentioned research is to ground theoretical-practical principles and recommendations concerning the basement of the directions of the artificial intelligence use in the management of economic and financial systems of the state in order to increase the competiveness of the economy of Ukraine.

\section{PREREQUiSITES FOR THE EMERGENCE AND USE OF THE ARTIFICIAL INTELLIGENCE}

Artificial intelligence is a young branch of science that began its development in the second half of the last century and aims to study the peculiarities of combining robotics and the human intelligence to increase the efficiency and the competitiveness level of subjects of various economic activities. Development of digital technologies and information society, intensification of competition, emergence of new needs of consumers of products and services, etc. have become the prerequisites for the creation and use of the artificial intelligence in financial and economic processes. The structure and components of the artificial intelligence system are shown in Fig. 1

Use of the artificial intelligence becomes particularly relevant in those spheres of economic activity that are subjected to constant influence of endogenous and exogenous factors, where there is a complex manufacturing process or concentric, conglomerate and horizontal diversification of services. 


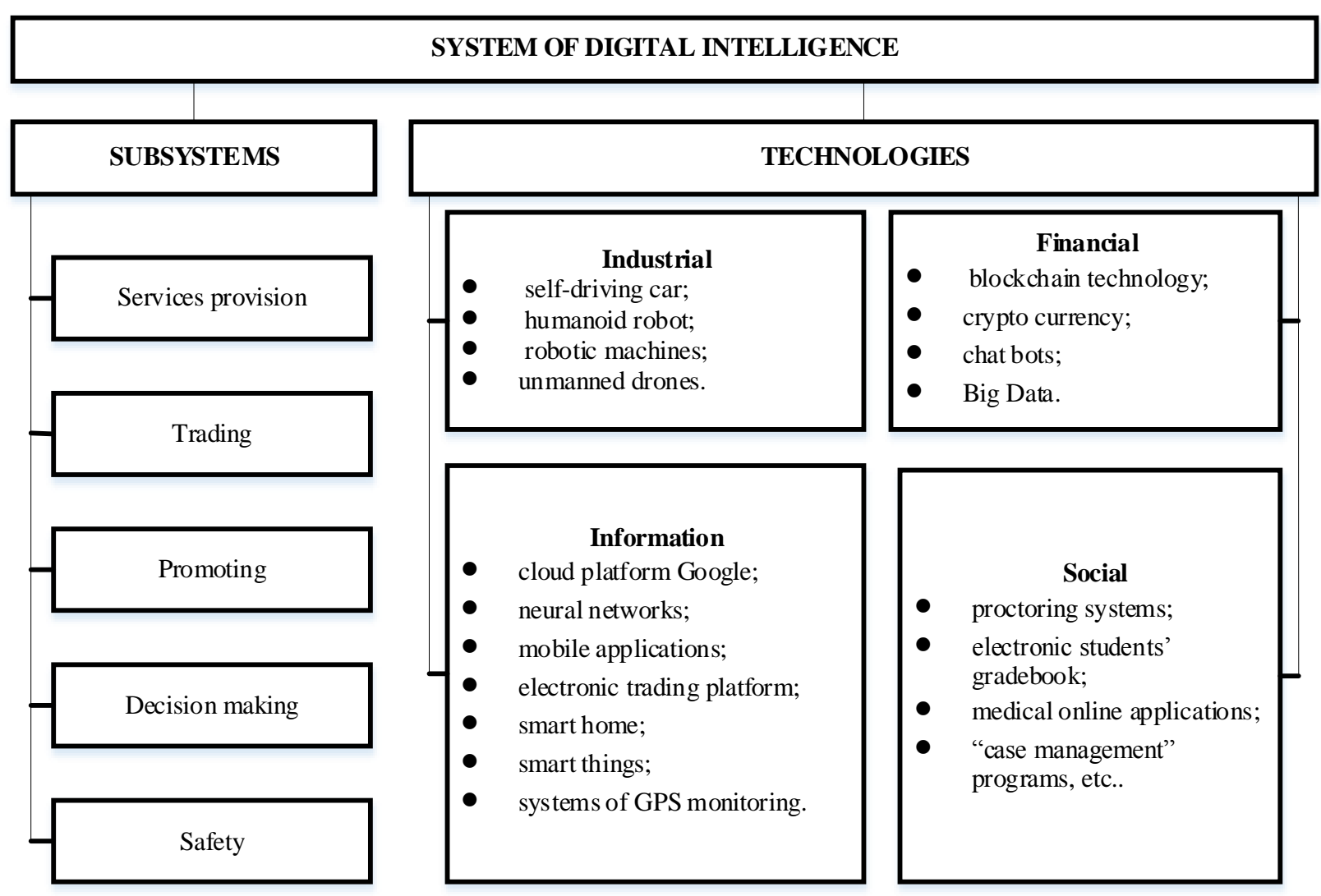

Fig. 1. Structure of the digital intelligence system

Source: compiled by authors

\section{ANALYSIS OF THE INFLUENCE STATE OF THE DigITAL INTELLIGENCE ON THE ECONOMIC SYSTEM DEVELOPMENT}

According to international organizations of practitioners and researchers in the field of the artificial intelligence, by 2030 the latter could provide world GDP growth for $14 \%$ or \$15.7 trillion US dollars. Rapid development of automation and robotics will help reduce the number of jobs and according to the forecast, about 800 million people may be left without work. Moreover, more than 375 million people will need to master new areas of economic activity, raising their level of skills and mastering the skills of a new profession. Development of digital technologies will lead to automation of about $1 / 3$ of the functions in $60 \%$ of the various professions, which by 2030 will lead to the elimination of 57 specialties $[13 ; 14]$. According to the report Artificial Intelligence Industry in Eastern Europe 2018 [15], compiled and published by Deep Knowledge Analytics, Ukraine in the year 2018 was among three Eastern European countries by the number of companies in the field of the artificial intelligence, which numbered 57 units. The first and second positions in the above-mentioned review on the number of companies in the field of the artificial intelligence are occupied by Russia - 133 units and Poland - 110 units, respectively. The report states that countries such as Russia, Belarus and Ukraine take an active part in international grants and international competitions on innovations in robotics. In addition, Ukraine, along with Russia, Poland, Lithuania, Estonia and Latvia, is attractive to the investors who are ready to invest in the development of the artificial intelligence technologies. In general, it should be noted that Ukraine, like most Western and Eastern European countries, lags behind the pace of development of the artificial intelligence, especially from countries such as the United States and China, which today are the leaders in the world for their development and implementation. In the future, this can lead to an even greater breakthrough in the technological development of our state, non-rivalry of domestic products and services in the world market, reduction of volumes of foreign economic activity and international technical consulting and financial assistance. The International Federation of Robotics conducts research in the field of the use of robots for industrial activities, business, etc., let's consider the study for 2012-2017 years (Fig. 2).

The figure shows the number of deliveries that do not include the current number of active industrial robotics. During the research, it was found that in 2017 their number amounted to 322 thousand pieces, which is $11 \%$ more than in 2016 - 290 thousand pieces. The general trend shows an increase in the supply of the artificial intelligence by 10 $20 \%$ annually compared with previous periods.

The International Federation of Robotics (IFR) predicted that by 2019 , the total number of robotics operating in the current year, taking into consideration all annual supplies, would be more than 2.5 million pieces in the field of 
industrial activity. One such robot can replace 1 to 10 specialists on average, and the amount of saved resources to pay salaries is difficult even to count [16].

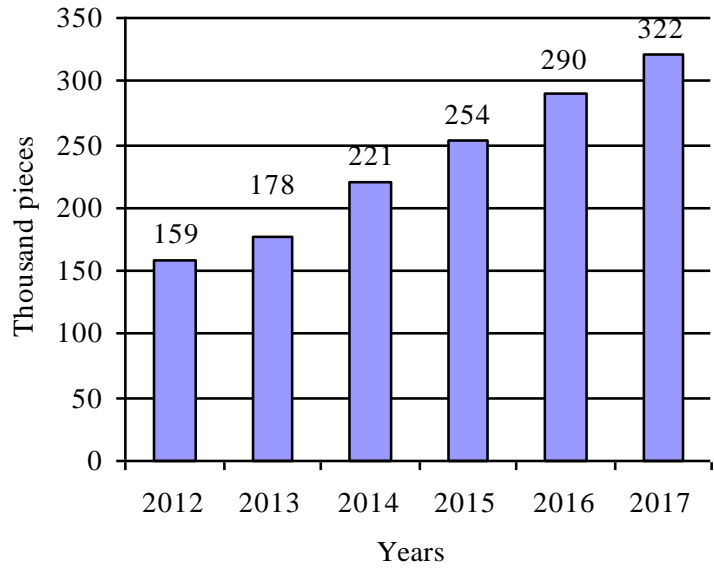

Fig. 2. Annual deliveries of industrial robots in the world from 20122017

Source: compiled by authors based on [16].

The analysis of the main areas of use and areas of activity of companies in the field of the artificial intelligence of Ukraine is presented in Table 1.

TABLE I. PRODUCTION AND DISTRIBUTION OF THE DIGITAL INTELLIGENCE IN UKRAINE

\begin{tabular}{|l|c|l|c|}
\hline $\begin{array}{l}\text { Areas of the artificial } \\
\text { intelligence use }\end{array}$ & $\begin{array}{c}\text { Values, } \\
\mathbf{\%}\end{array}$ & $\begin{array}{c}\text { Areas of companies' } \\
\text { activity in the field of } \\
\text { the artificial intelligence }\end{array}$ & $\begin{array}{c}\text { Values, } \\
\text { \% }\end{array}$ \\
\hline Machine Learning & 26,3 & Computer Software & 38,18 \\
\cline { 3 - 4 } & 26,3 & $\begin{array}{l}\text { Information Technology } \\
\text { Chat bots and artificial } \\
\text { intelligence Assistants }\end{array}$ & 14,55 \\
\hline Internet of things & \multirow{2}{*}{$\begin{array}{l}\text { Search Engines and } \\
\text { Language Processing }\end{array}$} & Fintech and Finance & 7,09 \\
\hline $\begin{array}{l}\text { Intelligent Data } \\
\text { Analysis }\end{array}$ & 8,8 & Entertainment & 7,27 \\
\cline { 3 - 4 } & & $\begin{array}{l}\text { Others } \\
\text { Advertising }\end{array}$ & 5,45 \\
\hline Computer Vision & 8,8 & $\begin{array}{l}\text { Transport and } \\
\text { Infrastructure }\end{array}$ & 5,45 \\
\hline Robotics & 7,0 & Healthcare & 3,64 \\
\hline Recommender Systems & 3,5 & Education and Research & 3,64 \\
\cline { 3 - 4 } & & Security & 1,82 \\
\hline
\end{tabular}

Source: compiled by authors based on [15].

As can be seen from Table 1, the key areas for using the digital intelligence in Ukraine are Machine Learning, Internet of things and Search Engines and Language Processing. Ukrainian companies in the field of the artificial intelligence are actively working on the development of software, information technology, creation of chat-bots and AI-assistants. At the same time, insignificant attention is paid to strategic directions of ensuring the effective and stable operation of the state's economic system in the areas of artificial intelligence development in such areas as transport and infrastructure, health care, science and research, as well as security.

In the conditions of the development of artificial technologies, creation of an appropriate legislative framework for the application of the artificial intelligence in economic activity should be the target of the state. In order to limit possibilities of the negative influence of the artificial intelligence on the state of the economic system, it is necessary to create appropriate bodies of the state executive power, the main functions and powers of which will be to regulate the impact of robotics on economic processes, control over cyberspace and create a system for instant response to cyber attacks.

Before we dwell on the directions of improving the management system of the economic system in the conditions of the artificial intelligence development, let us dwell on the consideration of the main threats to its widespread use in the economy.

Among the threats of macro- and micro-character are the following:

- exclusion of the influence of the human factor on the sphere of emergency response to inquiries, applications and conclusion of transactions;

- $\quad$ reducing the number of jobs and as a result of rising unemployment;

- increase in social tension in the society, especially among the representatives of the middle class;

- decrease in the volume of tax revenues to the budgets of all levels and the amount of deductions of individuals and legal entities to state target funds;

- formation of the dependence of the overwhelming majority of people on the use of artificial intelligence and the inability to make decisions on their own;

- deepening disproportions of the population access to resources;

- lack of an effective system of monitoring and control of the impact of artificial intelligence technologies on the development of the society, access to personal data and loss of their confidentiality;

- emergence of situations of independent decision making by the artificial intelligence without the consent of the developers;

- $\quad$ increase of scrap waste and necessity of enterprises construction for their processing;

- increase of emissions of harmful substances into the atmosphere;

- increase the likelihood of cyber-attacks and increase the costs for overcoming their consequences.

The main problems in the development and implementation of the artificial intelligence are:

- absence of the state strategy for the development of the artificial intelligence in various spheres of the economic activity; 
- lack of a legal basis for defining the limits of responsibility of the developer and the user of technologies of the artificial intelligence and the developed system of cyber insurance;

- shortage of funds for carrying out systematic research on the use of the artificial intelligence in various spheres of the economic activity;

- lack of the methodology for assessing the level of bias and justice in the application of the artificial intelligence in such activities as justice, health care, education;

- existence of information barriers due to the complexity and large amount of information on the development and use of the artificial intelligence and the impossibility of timely and complete analysis and processing;

- lack of the education system from the requirements of training of modern highly skilled specialists in different spheres of the artificial intelligence use, etc.

\section{CONCLUSIONS}

Elimination of the abovementioned threats and problems requires improvement of the state regulation system in the field of introduction and development of the artificial intelligence in Ukraine. First of all, it is necessary to develop a national strategy for the development of the artificial intelligence technologies, in which it is necessary to describe the mechanism of the development of publicprivate partnership in the field of the innovations dissemination, to clearly state the measures aimed at preventing the economic, financial, social crisis in the state, which may arise in the case of the practical use of the artificial intelligence. It is also necessary to increase the level of interaction between the state, business and science by studying the real needs of subjects of different types of economic activity in new technologies and assessing the real possibilities of their satisfaction. The amount of public funding for the fundamental research and development, which, for example, is carried out by the Institute for the Digital Intelligence Problems of the National Academy of Sciences of Ukraine, needs to be increased. State support for startup projects should include measures for the creation and development of appropriate digital infrastructure.

Rapid development of the competition in the technology market necessitates the development of appropriate state programs for the introduction of the artificial intelligence into the economic system of the state, namely:

- $\quad$ programs to support the introduction of the artificial intelligence at enterprises with harmful and hazardous working conditions, which lead to the occurrence of injuries or mortality - mining, chemical industry, etc.;

- programs for the development of intellectual transport and logistics systems;
- programs for the development of grant financing and investment attraction to support start-up projects;

- programs for introducing the artificial intelligence into the system of public administration, defense and security;

- programs for applying artificial intelligence technologies in the social sphere;

- $\quad$ programs of the digital infrastructure development.

Practical implementation of the above measures will enable the development of new instruments of the state policy of the economic system management in the conditions of the development and penetration of the artificial intelligence into all spheres of economic life.

\section{REFERENCES}

[1] O. V Palagin, O. P. Kurgayev, and A. I. Shevchenko "Noospheric paradigm of the development of the science and digital intelligence", Cybernetics and system analysis, vol. 53, no. 4. pp. 12-21, 2017.

[2] J. Barrat, Our final invention: artificial intelligence and the end of the human era. New York, USA: Thomas Dunne Books, St. Martin's Griffin, 2015.

[3] D. Francescato, "Globalization, artificial intelligence, social networks and political polarization: New challenges for community psychologists", Community Psychology in Global Perspective, vol. 4, no. 1, pp. 20-41, 2018. DOI 10.1285/i24212113v4i1p20.

[4] N. Bostrom, Superintelligence: Paths, Dangers, Strategies. Oxford, UK: Oxford University Press, 2014.

[5] S. Hawking, The Large, the Small and the Human Mind. Oxford, UK: Oxford University Press, 2000.

[6] P. Tullini, "Digital economy and non-standard work", Labour \& Law Issues, vol. 2, no. 2, pp. 1-15, 2016. DOI 10.6092/issn.24212695/6489.

[7] V. I. Liashenko, and O. S. Vyshnevsky, Digital modernization of the economy of Ukraine as an opportunity of breakthrough development: monograph, Kyiv, Ukraine: National Academy of Sciences of Ukraine, 2018.

[8] A. V. Matviychuk, Digital intelligence in economy: neural networks, fuzzy logics: Monograph. Kyiv, Ukrane: KNEU, 2011.

[9] K. Kelly, The Inevitable: Understanding the 12 Technological Forces That Will Shape Our Future Paperback. Colchester, UK: Penguin Books, 2017.

[10] J. Balicki, "Some paradigms of artificial intelligence in financial computer systems", Contemporary Economy, vol. 6, no. 4, pp. 1-23, 2015 .

[11] D. Markoff, Homo Roboticus? Humans and machines searching for mutual understanding. Moscow, Russia: Alpina-non-fiction, 2016.

[12] V. P. Karchevsky, "A human and a robot. Development of learning processes", Digital intelligence, no. 4, pp. 43-52, 2012.

[13] Everest Innovation Integrator. [Online]. Available: https://www.everest.ua/. Accessed on: May 22, 2019.

[14] McKinsey Global Institute. [Online]. Available: https://www.mckinsey.com/mgi/overview. Accessed on: May 23, 2019.

[15] AI in Eastern Europe. Artificial intelligence industry landscape overview 2018. [Online]. Available: http://analytics.dkv.global/data/pdf/AI-in-EE/AI-in-Eastern-EuropeInfographic-Summary.pdf. Accessed on: May 25, 2019.

[16] International Federation of Robotics (IFR). [Online]. Available: https://www.ifr.org/news/ifr-press-release/world-robotics-report2016-832/. Accessed on: May 23, 2019. 